\title{
Double aortic arch with double aneuploidy-rare anomaly in combined Down and Klinefelter syndrome
}

\author{
Maaike F. Gerretsen • Willem Peelen • \\ Lukas A. J. Rammeloo • David R. Koolbergen • \\ Jaroslav Hruda
}

Received: 13 January 2009 / Accepted: 13 February 2009/Published online: 5 March 2009

(C) The Author(s) 2009. This article is published with open access at Springerlink.com

\begin{abstract}
A 14-month-old boy with double aneuploidy and a double aortic arch suffered from frequently recurrent severe feeding and respiratory problems. Chromosomal analysis showed a 48,XXY + 21 karyotype: a double aneuploidy of Down syndrome (DS) and Klinefelter syndrome (KS). Only four cases of double aneuploidy (DS $+\mathrm{KS}$ ) associated with congenital heart defects have been published of which none had a double aortic arch. Our case report should draw attention to the possibility of a double aortic arch in patients with severe feeding and respiratory problems and a double aneuploidy.
\end{abstract}

Keywords Double aneuploidy · Down syndrome .

Klinefelter syndrome $\cdot$ Double aortic arch $\cdot$ Vascular ring

\section{Introduction}

The first case of double aneuploidy of Down syndrome (DS) combined with Klinefelter syndrome (KS) was published in 1959 by Ford et al. [8]. Most of the papers published since then were focused to more extent on the

M. F. Gerretsen • L. A. J. Rammeloo · J. Hruda $(\bowtie)$

Department of Pediatric Cardiology,

VU University Medical Center,

Amsterdam, The Netherlands

e-mail: j.hruda@vumc.nl

W. Peelen

Department of Pediatrics, St. Jansdal Hospital,

Harderwijk, The Netherlands

D. R. Koolbergen

Department of Cardiothoracic Surgery, Academic Medical Center, Amsterdam, The Netherlands double aneuploidy itself than on the clinical features of the patients. Pediatric cardiologists are familiar with screening of babies with DS for congenital heart defects (CHD), expecting in approximately $50 \%$ to find a heart defect, typically atrioventricular septal defect $[9,13]$. However, in children diagnosed with KS, a CHD has only rarely been reported [1, 13, 15]. Reports on CHD with double aneuploidy of DS and KS are scarce. We report on a child with DS and KS associated with a double aortic arch.

\section{Case report}

A 14-month-old boy was admitted to our department after frequent admissions in other hospitals because of recurrent severe feeding and respiratory problems. His weight was $7.6 \mathrm{~kg}$, height $78 \mathrm{~cm}$, blood pressure $90 / 75 \mathrm{mmHg}$, moderate psychomotor retardation was present. His parents were not consanguineous. He was born following an uneventful pregnancy with a birth weight of $2,560 \mathrm{~g}$. The mother was 36 years old.

Chromosomal analysis performed because of facial dysmorphic features (Fig. 1) suggesting Down syndrome revealed a 48,XXY 21 karyotype: a double aneuploidy of Down syndrome and Klinefelter syndrome. Soon after birth, he had to be intubated because of severe respiratory problems. Echocardiography, bronchoscopy and CT thorax performed in another centre demonstrated a small atrial septal defect (secundum type) and narrowing of the trachea from its middle to the carina. The X-ray of the small bowel was normal; barium swallow was then not performed. The boy had to be fed by a tube and later exclusively via a percutaneous endoscopical gastrostomy. After extubation, the patient suffered repeatedly from severe respiratory distress in the course of intercurrent infections. 


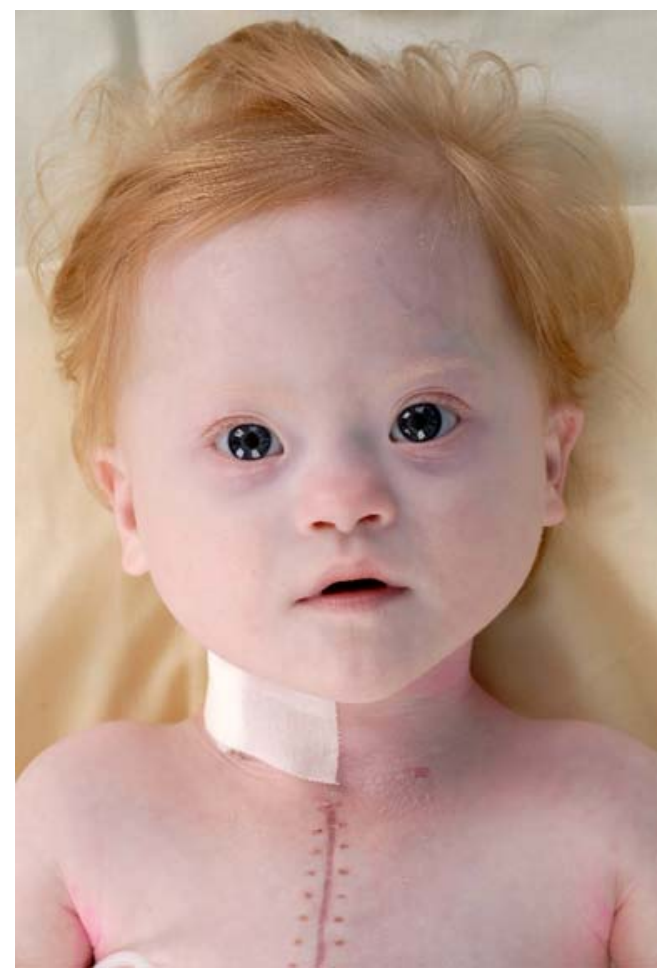

Fig. 1 Facial dysmorphic features in a child with double aneuploidyDown syndrome and Klinefelter syndrome (with the permission of the parents)

This clinical picture accompanied by findings of a topical trachea and possibly also an oesophageal obstruction led to a suspicion of a vascular airway compression. A new echocardiography and a new CT of the thorax with contrast (Siemens Somatom Sensation 64-slice, contrast $25 \mathrm{ml}$ omnipaque 300 intravenous) demonstrated a double aortic arch (Fig. 2), compressing both trachea and oesophagus. The anterior left arch appeared smaller with a localised narrowing, as compared to the posterior right

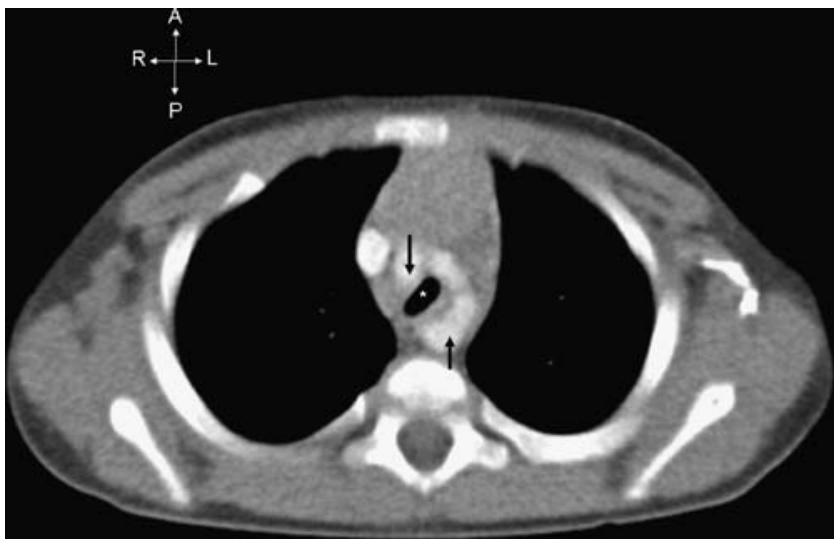

Fig. 2 CT scan, transverse projection. Arrows indicate anterior and posterior aortic arch. Trachea (asterisk) compressed by the vascular ring. $A$ anterior, $L$ left, $P$ posterior, $R$ right arch. The descending aorta was running to the left of the spine. Barium swallow demonstrated a severe indentation in the proximal oesophagus (Fig. 3).

Using a median sternotomy approach, the left anterior aortic arch was divided at the smallest point between the left carotid and subclavian artery. In addition, the ductal ligament was divided. Complete and thorough mobilization of the trachea and oesophagus has been performed. It was decided not to proceed with open heart surgery in order to close the small centrally located atrial septal defect, because if still necessary, it can later be closed percutaneously.

The postoperative course was complicated by a wound infection and pleural empyema for which he needed surgical treatment. The percutaneous endoscopical gastrostomy could be abolished and normal oral feeding restored.

\section{Discussion}

Aneuploidy is defined as an abnormal number of chromosomes. Double aneuploidy, the existence of two chromosomal abnormalities in the same person, is relatively rare. It can involve both autosomal (chromosome 13,18 or 21) and

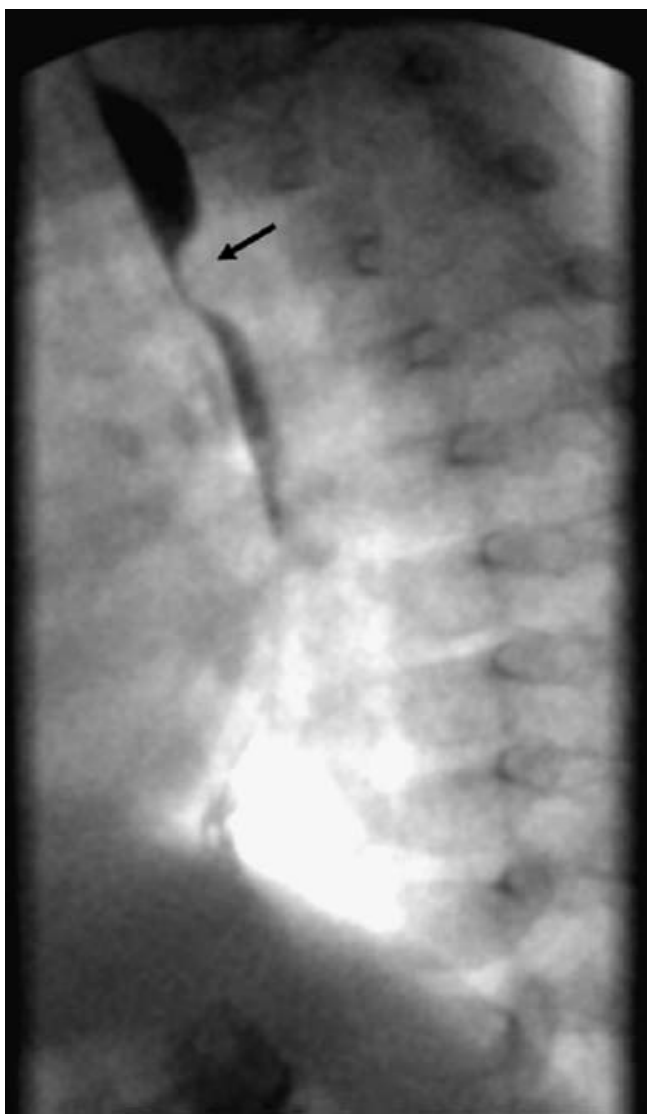

Fig. 3 Barium swallow. Posterior indentation of the oesophagus (arrow) 
sex chromosomes [17] and each may manifest either as a monosomy or trisomy or even tetra- or pentasomy.

The incidence of a double aneuploidy with DS and KS varies in different publications [11]. Kovaleva and Mutton [12] have reported that $0.098 \%$ of the children with DS also have KS.

The incidence and spectrum of cardiovascular anomalies in children born with Down-Klinefelter syndrome is not known. Only four case reports on CHD in these patients have been published $[2,6,7,11]$, but none had a double aortic arch.

Adult patients with isolated KS may occasionally suffer from mitral valve prolapse. However, an obvious relationship between this syndrome and CHD has not been documented, with exception of several case reports $[1,15]$. In contrast, Down syndrome alone is well known for cardiac anomalies, occurring in $40 \%$ to $50 \%$ of patients [13]. Freeman [9] reported a $44 \%$ incidence of CHD in a group of 227 infants with DS, of which $45 \%$ are atrioventricular, $35 \%$ are ventricular and $8 \%$ had an isolated atrial septal defect. The resting $12 \%$ of other anomalies did not include any infant with a vascular ring. As a matter of fact, an aberrant origin of the subclavian artery (arteria lusoria) seems to be found more and more frequently in children with DS, so that it has even been proposed to consider it as a new cardiac sign for DS [5]. In most of them, however, this should be only an incidental finding [14], not responsible for the feeding difficulties. Interestingly, in patients with DS less vascular anomalies than in general population were reported, probably because of an increase in inhibitors of vascular endothelial growth factor, whose genes are located on chromosome 21 [10]. Double aortic arch does not belong to the spectrum of defects known to be associated with DS.

Our observation should draw attention to a possible occurrence of a complete vascular ring in a young infant with clinical symptoms of recurrent respiratory and feeding problems and a (double) aneuploidy. In addition to assessing intracardiac anatomy, a careful assessment of aortic arch anatomy is warranted $[3,4,16]$ before possible breathing or swallowing difficulties may be assigned to muscular hypotony, bronchial pathology and other factors, common for patients with (double) aneuploidies.

Conflict of interests The authors declare that they have no conflict of interest.
Open Access This article is distributed under the terms of the Creative Commons Attribution Noncommercial License which permits any noncommercial use, distribution, and reproduction in any medium, provided the original author(s) and source are credited.

\section{References}

1. Adatia I, Coe JY, Harder J (1987) Transposition of the great arteries in a neonate with Klinefelter's syndrome. Pediatr Cardiol 8:285-286

2. Akbas E, Soylemez F, Savasoglu K et al (2008) A male case with double aneuploidy $(48, \mathrm{XXY},+21)$. Genet Couns 19:59-63

3. Alsenaidi K, Gurofsky R, Karamlou T et al (2006) Management and outcomes of double aortic arch in 81 patients. Pediatrics 118 : e1336-e1341

4. Bakker DA, Berger RM, Witsenburg M et al (1999) Vascular rings: a rare cause of common respiratory symptoms. Acta Paediatr 88:947-952

5. Chaoui R, Heling KS, Sarioglu N et al (2005) Aberrant right subclavian artery as a new cardiac sign in second- and third-trimester fetuses with Down syndrome. Am J Obstet Gynecol 192:257-263

6. Efinski D, Duma H, Apostolovski B et al (1974) Klinefelter's and Down's syndrome in an adolescent with abnormal EEG. Clin Genet 5:81-85

7. Erdtmann B, de Freitas AA, de Souza RP et al (1971) Klinefelter's syndrome and G trisomy. J Med Genet 8:364-368

8. Ford CE, Jones KW, Miller OJ et al (1959) The chromosomes in a patient showing both mongolism and the Klinefelter syndrome. Lancet 1:709-710

9. Freeman SB, Taft LF, Dooley KJ et al (1998) Population-based study of congenital heart defects in Down syndrome. Am J Med Genet 80:213-217

10. Greene AK, Kim S, Rogers GF et al (2008) Risk of vascular anomalies with Down syndrome. Pediatrics 121:e135-e140

11. Hecht F, Nievaard JE, Duncanson N et al (1969) Double aneuploidy: the frequency of XXY in males with Down's syndrome. Am J Hum Genet 21:352-359

12. Kovaleva NV, Mutton DE (2005) Epidemiology of double aneuploidies involving chromosome 21 and the sex chromosomes. Am J Med Genet A 134A:24-32

13. Pierpont ME, Basson CT, Benson DWJ et al (2007) Genetic basis for congenital heart defects: current knowledge: a scientific statement from the American Heart Association Congenital Cardiac Defects Committee, Council on Cardiovascular Disease in the Young: endorsed by the American Academy of Pediatrics. Circulation 115:3015-3038

14. Roofthooft MTR, van Meer H, Rietman WG et al (2008) Down syndrome and aberrant right subclavian artery. Eur J Pediatr 167:1033-1036

15. Rosenthal A (1972) Cardiovascular malformations in Klinefelter's syndrome: report of three cases. J Pediatr 80:471-473

16. Turner A, Gavel G, Coutts J (2005) Vascular rings - presentation, investigation and outcome. Eur J Pediatr 164:266-270

17. Zaki MS, Kamel AA, El-Ruby M (2005) Double aneuploidy in three Egyptian patients: Down-Turner and Down-Klinefelter syndromes. Genet Couns 16:393-402 